\title{
Assessment of ASP-PMIS Quality in Korea
}

\author{
SeulKi Lee ${ }^{1}$ and Jung Ho Yu ${ }^{2}$
}

\begin{abstract}
Web-based PMIS (Project Management Information System) has played significant role in construction management processes in Korea. As the use of web-based PMIS increases, regular quality assessment to identify user's requirements is necessary. However, there have been rare research efforts for quality assessment of web-based PMIS. This study aims to assess the quality of web-based PMIS, especially ASP-PMIS (Application Service Provider based PMIS) that is widely used in Korean construction industry. The assessment factors of ASP-PMIS quality were adopted from previous research and empirically confirmed using exploratory factor analysis. ISA (Importance-Satisfaction Analysis), which is a variation of original IPA (Importance-Performance Analysis), were selected for the assessment and analysis method in this research. A total of 253 completed questionnaires, composed of 23 assessment items, were collected from the ASP-PMIS users in Korea (construction managers and constructors), and they were used to analyse the quality of the systems. Some possible contributions of this research are: it introduces a simple and easy-to-use tool for assessing the quality of ASP-PMIS with a set of quality assessment factors that are selected from previous researches and empirically tested; it provides the quality assessment results of ASP-PMIS in Korea so that ASP-PMIS providers in Korea can understand the users' opinion on their systems; it also identified that the urgent factors that require immediate attention to improvement. However, further researches are to be required on the following areas: enhancing the quality assessment factors in terms of their relation to the success of ASP-PMIS and to the users' performance; assessing and analyzing the quality of individual ASP-PMIS; establishing continuous improvement systems institutionally and instrumentally.
\end{abstract}

Keywords: Project Management Information System(PMIS), Quality, Importance-Satisfaction Analysis(ISA)

\section{INTRODUCTION}

\section{A. Background and Objective}

The Architectural, Engineering, and Construction (AEC) industry is characterized by fragmentation, and this fragmentation exists both within individual phases as well as across project phases (Howard et al. 1989). Because of this fragmentation, participants from various organizations, who are involved in a project phase or in different project phases, are facing ineffectiveness and inefficiency problems in their coordination, collaboration and communication processes. As a tool to reduce the problems generated by the fragmentation, Information Technology (IT) is routinely and extensively used in the construction industry (Nitithamyong and Skibniewski 2004). This is because the use of IT improves coordination and collaboration among participants in a construction project, leading to better communication practices (Rojas and Songer 1999).

Among various IT solutions, internet-based (or webbased) Project Management Information System (PMIS, which is also called PMS as an abbreviation of Project Management System) has been spotlighted because of its strong advantages such as: low cost compared with traditional communication methods, location-free access, speedy and reliable data transfer and storage, and efficient information sharing among parties (Tam 1999; Deng et al. 2001; Nitithamyong and Skibniewski 2006).
The Engineering New Record (ENR) has also reported the increased use of web-based PMS (Hurtado 2003). The situation is very similar in Korean construction industry.

Web-based PMIS has become one of the most widely used tool that supports and enhances the collaboration and communication between construction project participants. The reason for the swift adoption of webbased PMIS in Korean construction industry closely relates not only to the above-mentioned advantages, but also to the well-established internet infrastructure and users'familiarity with web-based computing environment. Besides these technical reasons, Construction Management Guidebook (MLTM 2001) that specifies the use of PMIS by construction managers hired by government or government agencies for efficient information management has strongly facilitated the adoption of web-based PMIS in Korean construction industry.

As the use of web-based PMIS has become a part of ordinary construction project management practice, the need to assess the quality of this kind of system is raised by two different parties: One is users who want to justify the investment on information systems or to rank the superiority among alternative systems, and the other is system providers who want to catch the users' opinion regarding their systems so that they can find where their

\footnotetext{
${ }^{1}$ PhD Student, Kwangwoon University, Seoul, Korea, selkizz@kw.ac.kr

${ }^{2}$ Associate Professor, Kwangwoon University, Seoul, Korea, myazure@kw.ac.kr (*Corresponding Author)
} 
systems need improvement. From the users' viewpoint, there has been various research for the evaluation or assessment of IT/IS or web-based PMIS in construction (Jung and Gibson 1999; Pena-Mora et al. 1999; Andersen et al. 2000; Marsh and Flanagan 2000; PenaMora and Tanaka 2002; Love et al. 2005; Stockdale et al 2006; Yu et al. 2006). Some research is focusing on measuring the appropriateness or readiness of construction management tasks toward the implementation of information systems, and other research is proposing frameworks or methods to measure the overall benefits of IT/IS implementation. However, there is relatively limited research on the evaluation or assessment of web-based PMIS from the system providers' viewpoint, even though this type of assessment is necessary to build up a continuous improvement plan of the systems. On the other hand, from the practical perspective of the Korean construction industry, even though web-based PMIS has been spread out over the last decade, there has not been much effort to assess the quality of web-based PMIS so far.

In this context, this paper aims to assess the quality of web-based PMIS which is widely used in Korean construction industry. For this purpose, a set of assessment factors that are empirically validated is proposed. In addition, an appropriate assessment and analysis method is selected among the most widely used methods. The assessment factors and analysis method, though they are adopted from previous research and combined in this research, will be found as simple and easy-to-use.

\section{B. Scope and Method}

According to a previous study (Nitithamyong and Skibniewski 2004), web-based PMIS or similarly called as WPMS (Web-based Project Management System) has three possible options of implementation: The first option for a company is to develop its own in-house system by utilizing its own IT organization or hiring outside consultants and system engineers. The second option is to purchase ready-to-use packaged software and install it on a company's internal server computer. Microsoft Project 2002 from Microsoft or P6 from Primavera are some examples of such a type of software. The third option is to rent a completely developed system from an Application Service Provider (ASP), in which case the usage fee may be charged per project or per user. Buzzsaw is one famous example of this type, and there are also a few of this type in Korea, i.e., Doall-PMIS, NOA-PMIS, and SangAh-PMIS, to name a few. The third type of PMIS, which will be named as ASP-PMIS hereinafter, offers ready-to-use systems with easy customization and requires minimal technical, financial, and human resources to develop and operate (Nitithamyong and Skibniewski 2006). Moreover, ASP-PMIS inherits most benefits of ASPbased information systems such as filling gaps in IT resources and capabilities to address problems or execute strategy, low level dependence for commodity applications offered by alternative suppliers, access to specialized technical solutions, and low transaction costs for commodity applications (Kern et al. 2002). Besides, the users of ASP-PMIS can enjoy the benefit of economy of scale. Because of these reasons, ASP-PMIS has become the most widely used type of PMIS in Korean construction industry. This research also limits its scope of study to this type of PMIS.

For the selection of an appropriate assessment and analysis method, we reviewed the most widely adopted methods for service quality assessment such as IPA (Importance-Performance Analysis) and SERVQUAL. After the scrutinization of their advantages and disadvantages, we have selected ISA (ImportanceSatisfaction Analysis), which is a variation of original IPA, for assessment and analysis method for this research.

On the other hand, in order to select a set of assessment factors of ASP-PMIS quality, we followed the following steps: First, possible assessment items were extracted based on the literature review on previous researches. Second, a questionnaire asking the importance and satisfaction level of each item was developed. Third, the questionnaire was reviewed in terms of redundancy and content validity by three experts in PMIS development, and then the items were adjusted. Fourth, users' opinions were collected by a questionnaire survey $(n=253)$ and the data were analysed through EFA. Here, the assessed importance values by users' were used. Fifth, according to the EFA results and the associated statistical tests, final assessment factors of ASP-PMIS were confirmed.

\section{ASSESSMENT METHOD OF ASP-PMIS QUALITY}

\section{A. Review of Extant Methods for Service Quality Analysis}

The two main research instruments that have been developed over the years to analyze the concepts of quality and customer satisfaction in the service industry are Importance-Performance Analysis (IPA) and SERVQUAL (Hudson et al. 2006). IPA, which uses a multi-property model as its conceptual basis, is an evaluation procedure that compares and analyzes each property's relative importance and performance simultaneously to measure user satisfaction. IPA was applied for the first time to analyze the achievement of the automobile business (Matilla and James 1977), and since then, IPA has been applied in diverse research fields such as medical examination, education, sports, psychology, and so forth. However, IPA has been criticized for some reasons. Oh (2001) indicated ten issues that should be addressed for IPA to become a more valid technique: the lack of a clear definition for the concept of importance, the mixed uses of importance and expectation, and the absence of guidelines for developing a set of attributes to be used, just to name a few. Nevertheless, IPA has gained 
popularity because of its advantages and easiness for use. First of all, IPA represents the analysis results visually so that the information can be easily recognized. This is possible because IPA can note simple differences and draw a two-dimensional chart of importance-performance as well to generate a priority list. Moreover, IPA has another strong advantage of being able to make four kinds of multifaceted decisions by comparing assessment values.

On the other hands, Tonge and Moore(2007) used satisfaction instead of performance as an unit of measuresin IPA. They applied Importance-Satisfaction Analysis (ISA) techniques to analyze experiences of marine park visitors. Because performance was used as the proxy to measure the quality of service, the satisfaction factor of the ISA technique could effectively measure the visitor's quality of experience. Since this research, there have been many other researches that apply ISA for assessing the service experience of users in various service industries such as tourism, library, airline and water-taxi (Park J.W. et al. 2008, Jung Y.M. et al. 2010, Park S.H. et al. 2008, Kim T.H. et al. 2009).

SERVQUAL, which is a also very commonly used model of service quality assessment, uses the gap between customers' expectation and perceived performance (Parasuraman et al. 1985,1988). SERVQUAL uses twenty-two items for measuring the service quality, which are categorized into five dimensions such as tangibles, reliability, responsiveness, assurance, and empathy. And in order to measure the service quality in question, each item is measured twice: the first is to determine customer's expectations about the firms in general within the service category in question before the service is provided; the second is to measure perceptions of performance of a particular firm after receiving the service from the specific firm. Over twenty years since its first appearance, SERVQUAL has been adopted in a variety of service industries in several countries. It is concise and easy to use by managers, and it has been referred to as a standard by some researchers (Llosa et al. 1998). However, there have been debates about various aspects of SERVQUAL: the use of difference score, its discriminant validity, its predictive validity, and its emphasis on process rather than outcome, to name a few. Nevertheless, despite the apparent shortcomings of SERVQUAL, many researchers and practitioners continue to find that it is useful for measuring service quality (Ladhari 2008).

\section{B. Selection of Method}

The ASP-PMIS quality is determined by users of the systems. As this analysis aims to find out which quality factors need more immediate improvement by the providers, it is very important to directly gather the individual users' opinion on the system and to synthesize them properly. In addition, to gather the users' assessment in an efficient and effective way, the method should be easily understood and applicable.

Based on the review of the two methods for service quality assessment, ISA was selected as the analysis method in this research. The reason is threefold. First, ISA inherits the graphically analytical capability of IPA so that the analyst can easily recognize and compare the priority among the quality factors. Second, SERVQUAL is more about a firm which provides the service in question. In contrast, ISA focuses on service itself so that the service providers of ASP-PMIS can better concentrate on the quality factors of their systems. Third, the application of ISA is easier than that of SERVQUAL. When SERVQUAL is applied, the expectation and the perceived performance are to be measured separately, i.e., before the service and after the service. However, in applying ISA, the importance and the satisfaction are measured simultaneously.

\section{Application Procedure of ISA}

In general, the application procedure of ISA consists of four steps: preparation, survey, creation of importance-satisfaction map, and analysis. This research also follows the procedure.

\section{Step 1: Preparation}

This step is to define the quality factors that are critical to the users of a certain service. This step is also to develop survey questions and to determine the scale to be used.

Step 2: Survey

This step is to collect data from customers through a survey. A group of customers will be asked to rank the importance and satisfaction level of each quality factor using the measuring scale provided in the questionnaire. Step 3: Creation of Importance-Satisfaction Map

This step is to plot an importance-satisfaction map based on the assessment data by users. In general, importance is the vertical axis and satisfaction is the horizontal axis. The mean values (mean value of importance and mean value of satisfaction) of all factors are marked on the grid. The grand mean values are used to delineate the quadrants.

Step 4: Analysis

The priority for improvement is analyzed based on the quadrant in which the data point is located. Figure 1 shows an important-satisfaction matrix, and each quadrant can be generally interpreted as follows:

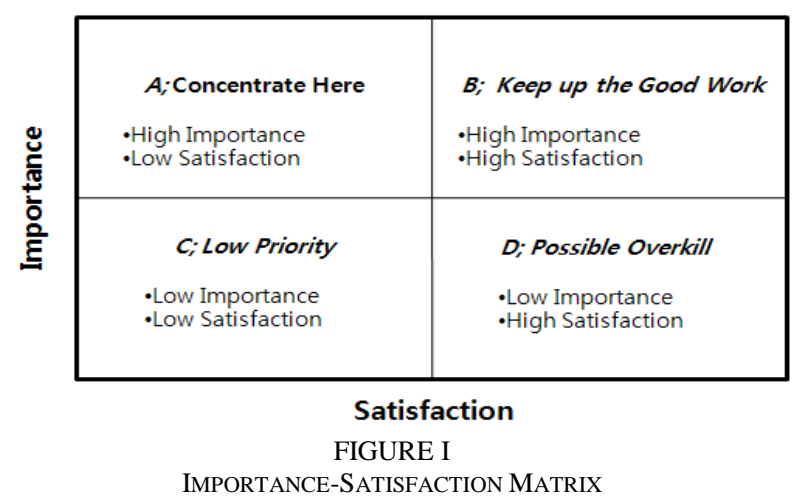


(A) Concentrate Here: Users consider a factor very important whereas the satisfaction level is low; improvement is worthwhile.

(B) Keep up the Good Work: Users consider a factor important and satisfactory as well. This means that most are satisfied with the current service and this level of service should continue.

(C) Low Priority: A factor in this quadrant means it is considered less important and satisfactory. Improvement is needed, but because the users do not consider the factor particularly important, improvement should not be the top priority.

(D) Possible Overkill: A factor in this quadrant means it is satisfactory but not important. In other words, users do not consider this characteristic to be important, so efforts for improvement should be focused elsewhere.

\section{ASSESSMENT FACTORS OF ASP-PMIS QUALITY}

\section{A. Review of Prior Studies on IS Assessment in Construction}

$\mathrm{Yu}$ et al. (2004) proposed and statistically verified four success factors of PMIS based on the characteristics of construction management tasks. The four factors are information usage level of a task, structuralization level of a task, information input easiness of a task, and contribution level of a task, and the research adopted Technology Acceptance Model (TAM, Davis 1989) to make itself theoretically sound. However, it dealt with only the first-type PMIS and the proposed success factors were tested using a dataset collected from only one construction company. Moreover, it is impossible to use these factors directly to assess the quality or performance of PMIS, because the proposed four factors are focusing on the characteristics of construction management tasks. Nitithamyong and Skibniewski (2006) proposed thirtysix potential performance measures of ASP-PMIS with six categories to qualify what is a good ASP-PMIS. Some of the performance measures in their study include; 'How much the system can reduce the marketing cost?', 'How much the system can reduce the number of RFIs?', 'How well the system can enable realizing cost savings?', and 'How easily the system can identify errors and inconsistencies?' However, as it can be understood from the above mentioned examples, these measures are more closely related to project performances rather than to the performance of an ASPPMIS itself. Chung et al. (2008) proposed and verified success factors of ERP (Enterprise Resource Planning) systems in construction industry. The factors are well arranged and tested according to theoretically proven models such as DeLoan and McLean's IS success model (DeLoan and McLean 1999, 2003) and TAM (Davis 1989, Venkatesh and Davis 2000). And the resulting success factors of ERP systems implementation in construction industry include user related variables such as output, job relevance, image, result demonstrability, compatibility, and system reliability and project related variables such as internal support, function, and consultant support. However, this research is only focused on ERP systems, even though it demonstrates a very good approach to building an IS success model in construction industry. Raymond and Bergeron (2008) suggested a PMIS success model which is also built upon previously verified models such as IS success model and TAM. In this model, PMIS Quality and PMIS Information Quality are used as the basic conceptual factors affecting the PMIS. To measure the PMIS Quality they used eight items such as accessibility, response time, flexibility, ease of use, querying ease, learning ease, systems integration and multi-project capability. And to measure the PMIS Information Quality they used six items such as availability, relevance, reliability, precision, comprehensiveness and security. This model seems theoretically well grounded, because it is based on previously proven theories. However, as the authors have mentioned, their validation test is relying on a very limited size sample.

\section{B. Selection of Factors}

The concept of Information System (IS) success is widely accepted for the evaluation of information systems (Lin et al. 2006). In the Management Information Systems (MIS) academia, wide ranges of research have proposed IS success models (DeLone and McLean 1992, 2003, Seddon and Kiew 1994, Seddon 1997, Pitt et al. 1995, Myers et al. 1997). These models postulate their own definition of IS success and factors that affect the defined IS success, and the models are theoretically grounded and empirically tested as well. Therefore, there have been various studies in which the success factors of the models are applied to the evaluation of IS success or performance.

A total of twenty-five quality factors of ASP-PMIS were initially selected from the above mentioned IS success models and other various researches as well (Jung and Jung 2005, Kim 2007, Park 2004, Joe and Lee 1997, DeLone and McLean 1992, 2003, Edward et al. 2005, Liu and Amett 2000, Han and Lim 1997, Ballou and Pazer 1987, Parasuraman et al. 1998). The factors were classified into three categories: system quality, information quality, and service quality, which are originally proposed by DeLone and McLean's IS success model (DeLone and McLean 2003). Then, a questionnaire was developed to collect the users' opinion on the current ASP-PMIS. The content validity of the twenty-five items in the questionnaire was tested through face-to-face interviews with three experts from three ASP-PMIS providers respectively. The experts' average experience in ASP-PMIS development was eight years, and they were asked to review the redundancy and adequacy of the quality factors of ASPPMIS in the questionnaire. After the interview, the number of the factors was reduced to twenty-three, which consists of seven for system quality, six for 
information quality, and ten for service quality.

The next step was testing the construct validity using an Exploratory Factor Analysis (EFA), which is generally used to identify a relatively small number of factor groups that can be used to represent relationships among sets of many inter-related variables. In the EFA, total of 253 users' responses were used that were collected by the developed questionnaire.

In general, two main issues need to be considered in determining whether a data set is suitable for factor analysis, which are the sample size and the strength of the relationship among the variables (Pallant 2001). In terms of a sample size, different researchers suggested different size of sample. Hair et al.(1998) argued an appropriate sample size should be at least 4-5 times of the number of variables, however, Nunnalyy (1978) suggested at least 10 times of the number of variables. In this study, the sample size was larger than 10 times of the number of variables, which was sufficient enough for factor analysis. On the other hand, in terms of the strength of relationship among the variables, the KaiserMyer-Olkin (KMO) (Kaiser 1970) test and the Bartlett's test of sphericity (Bartlett 1954) were recommended. The KMO index is a measure of sampling adequacy, and the sphericity statistic tests whether the correlations among variables are too low for the factor model to be appropriate. For the KMO index of sampling adequacy, value above 0.6 is required for good factor analysis, and our value of 0.95 was satisfactory. For Bartlett's test of sphericity, the significant value less than $0.05(\mathrm{p}<0.05)$ is required and ours was satisfactory. Therefore, the results of these tests confirmed that the data were appropriate for factor analysis.

The criteria used in the EFA were 'eigenvalues greater than 1' and 'factor loadings greater than 0.5 ' (Norusis 1992, Li et al. 2005, Aksorn and Hadikusumo 2008). Eigenvalues determine number of factors. The sum of the squared loadings of the variables on a factor is known as the eigenvalue of the factor. Dividing the eigenvalue by the number of variables gives the proportion of variance explained by the factor. The higher the eigenvalue, the higher the proportion of variance explained by the factor, so it is possible to set a criterion eigenvalue for the acceptance of a factor as being important enough to consider. By convention, the usual criterion value is 1 . In this study, we used principal component analysis with varimax rotation as the method for data analysis. The factor analysis identified three factor groups: system quality with five factors, information quality with ten factors, and service quality with eight factors.

Finally, reliability of the factors was tested using a Cronbach's coefficient alpha value. The Cronbach's Alpha's value considered to be acceptable is 0.6 (Nunnally 1978). The test result showed that the Cronbach's $\alpha$ ranged from 0.835 to 0.941 and confirmed that the measures used in the assessment were statistically reliable. The process of selecting quality factors of ASP-PMIS is explained more in detail in the authors' previous study (Lee and $\mathrm{Yu}$ 2011), and the resulting quality factors are summarized in Table 1.

TABLE I

ASP-PMIS QUALITY FACTORS

\begin{tabular}{|c|c|c|}
\hline Items & & Sub-Items \\
\hline \multirow{5}{*}{$\begin{array}{l}\text { System } \\
\text { Quality } \\
\quad(5)\end{array}$} & 1 & $\begin{array}{l}\text { PMIS should be compatible with oth } \\
\text { softwares (e.g., such as Excel, P3, CAD) }\end{array}$ \\
\hline & 2 & $\begin{array}{l}\text { PMIS should connect to other IT tools (e.g., } \\
\text { such as PDA, RFID, USN) }\end{array}$ \\
\hline & 3 & $\begin{array}{l}\text { Data input/output functions should be } \\
\text { operated easily (e.g., up/download, printing) }\end{array}$ \\
\hline & 4 & Access to system should be not difficult \\
\hline & 5 & System should maintain the stable state \\
\hline \multirow{10}{*}{$\begin{array}{l}\text { Informati } \\
\text { on } \\
\text { Quality } \\
\text { (10) }\end{array}$} & 1 & $\begin{array}{l}\text { System functions and configuration should } b \\
\text { related to required information }\end{array}$ \\
\hline & 2 & $\begin{array}{l}\text { System screen configuration or document } \\
\text { formats should be suitable for information } \\
\text { use }\end{array}$ \\
\hline & 3 & Search of information should be easy \\
\hline & 4 & $\begin{array}{l}\text { PMIS should offer information to users on } \\
\text { real time }\end{array}$ \\
\hline & 5 & Information in system should be reliable \\
\hline & 6 & $\begin{array}{l}\text { Information in system could be used without } \\
\text { correction }\end{array}$ \\
\hline & 7 & Information in system should be sufficient \\
\hline & 8 & $\begin{array}{l}\text { Information in system should be related to } \\
\text { user's task }\end{array}$ \\
\hline & 9 & $\begin{array}{l}\text { Information in system should be related to } \\
\text { project characteristics and user's role }\end{array}$ \\
\hline & 10 & $\begin{array}{l}\text { Options for information usage should be } \\
\text { various depending on the user's task }\end{array}$ \\
\hline \multirow{8}{*}{$\begin{array}{l}\text { Service } \\
\text { Quality } \\
\quad(8)\end{array}$} & 1 & $\begin{array}{l}\text { Reaction of PMIS service provider should be } \\
\text { quick in the situation }\end{array}$ \\
\hline & 2 & $\begin{array}{l}\text { Technical support of PMIS service provider } \\
\text { for maintenance and repair should be quick. }\end{array}$ \\
\hline & 3 & $\begin{array}{l}\text { Education for PMIS users should be } \\
\text { provided adequately }\end{array}$ \\
\hline & 4 & $\begin{array}{l}\text { User's manual and advice should be provided } \\
\text { adequately during use }\end{array}$ \\
\hline & 5 & $\begin{array}{l}\text { PMIS service provider should possess } \\
\text { knowledge of construction field }\end{array}$ \\
\hline & 6 & User should feel safe regarding data security \\
\hline & 7 & $\begin{array}{l}\text { User should trust capability of PMIS service } \\
\text { provider }\end{array}$ \\
\hline & 8 & PMIS service provider should be faithful \\
\hline
\end{tabular}

\section{ASSESSMENT OF ASP-PMIS QUALITY IN KOREA}

\section{A. Overview of Case Study}

This case study aimed to assess the quality of ASPPMIS which are widely used in Korean construction industry. We used the selected quality factors (twenty three factors) and assessment method (ISA), which are introduced and explained in part II and III. The data used for quality assessment were obtained from a sample of experienced ASP-PMIS users among construction managers and contractors. This is because, in general, the major users of ASP-PMIS in Korean domestic construction projects are construction 
managers and contractors. A total of 253 responses were valid and used for the analysis. Among 253 respondents, 140 were from construction management organizations and 113 were from contractor organizations. And the responses were collected from total of thirty-five projects, which consist of sixteen public projects and nineteen private projects. Besides, each item was measured on a 7-point Likert scale, with anchors ranging from 'strongly disagree' to 'strongly agree,' which is the most common scale being adopted in IPA or ISA. The questionnaire was sent by e-mail through project directors of each organization. The descriptive statistics relating to the respondents' characteristics are shown in Table 2.

TABLE II

CHARACTERISTICS OF THE RESPONDENTS (N=253)

\begin{tabular}{c|c|c|c}
\multicolumn{4}{c}{ CHARACTERISTICS OF THE RESPONDENTS (N=253) } \\
\hline Description & Frequency & $\%$ \\
\hline \multirow{2}{*}{ Project Type } & Public Project & 113 & $44.7 \%$ \\
& Private Project & 140 & $55.3 \%$ \\
\hline \multirow{2}{*}{ User Type } & Construction & 140 & $55.3 \%$ \\
& Managers & 113 & $44.7 \%$ \\
\hline \multirow{3}{*}{ Experience } & Contractors & 42 & $16.60 \%$ \\
In & Less than 2 years & 41 & $16.21 \%$ \\
Construction & $5 \sim 10 y e a r s$ & 53 & $20.95 \%$ \\
& $10 \sim 15 y e a r s$ & 27 & $10.67 \%$ \\
& More than 15years & 90 & $35.57 \%$ \\
\hline \multicolumn{2}{c}{ Respondents' Average PMIS Use } & 4.69 (hours per day) \\
\hline
\end{tabular}

\section{B. Assessment Results}

\section{1) $C M$ Group}

Importance-Satisfaction Analysis of the CM group is showed in Figure 2. First, importance is high whereas satisfaction is low in the 'PMIS should offer information to users on real time (InQ-4)', which belongs in the 'A-Concentrate Here' domain. Therefore, it is a main improvement factor.

In the 'B-Keep up the Good Work' domain, the importance and satisfaction show similar levels in InQ2, InQ-3, SeQ-1, SyQ-4, InQ-8, SyQ-3, and SeQ-8, and thus the current state needs to be maintained. Besides, 'System should maintain the stable state (SyQ-5)', 'Information in system could be used without correction (InQ-6)', and 'Information in system should be sufficient (InQ-7)' are also plotted in domain-B. However, satisfaction was relatively lower than the importance, and thus, continuous effort to improve satisfaction is needed for SyQ-5, InQ-6 and InQ-7.

In the 'C-Low Priority' domain, the importance and satisfaction showed similar levels in InQ-10, SeQ-5, SeQ-4, InQ-9, and SeQ-6, thus their current states need to be maintained with no priority. However, the satisfaction was higher than importance in SyQ-1. Accordingly, investment here is not necessary and an understanding of why importance and satisfaction are lower is needed. Besides, 'PMIS should be compatible with other softwares (SyQ-2)' and 'Education for PMIS user should be provided adequately (SeQ-3)' showed lower importance and satisfaction, with satisfaction still relatively lower than importance; therefore, attention is needed for these factors.

Finally, SeQ-7, SeQ-2, InQ-5 and InQ-1 belong to the 'D-Possible Overkill' domain, and the satisfaction is relatively high compared with the importance. Therefore the current state needs to be maintained and while being wary of over investment.

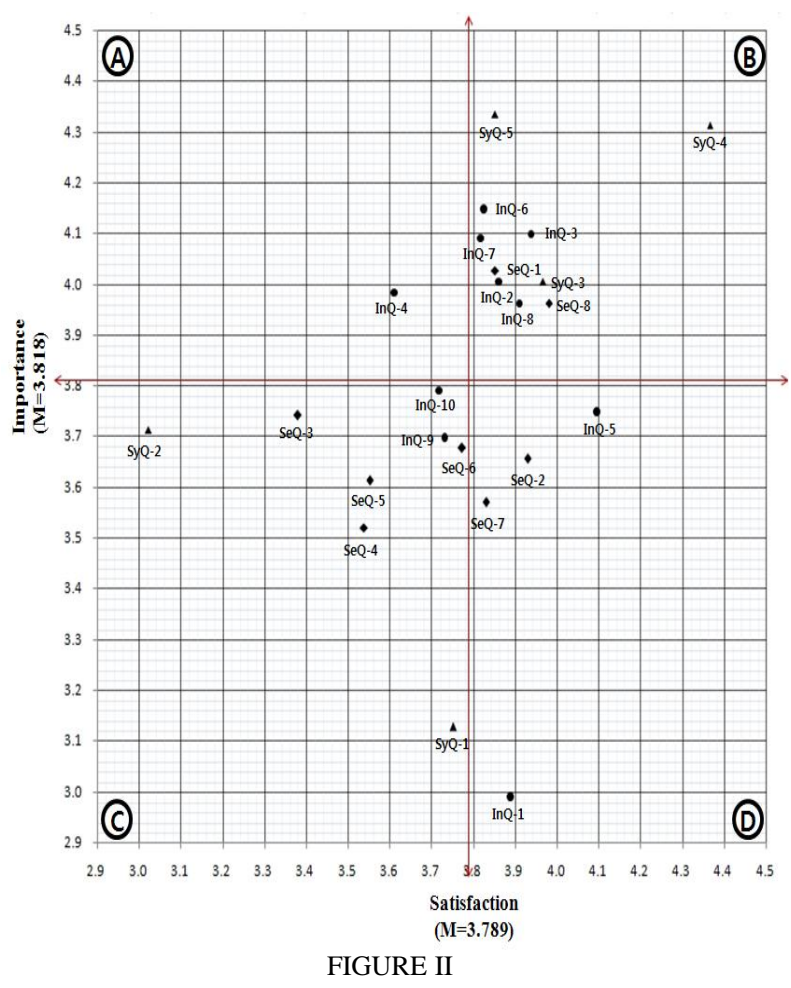

ISA RESULT OF CONSTRUCTION MANAGER

\section{2) Contractor Group}

Importance-Satisfaction Analysis of the Contractor group is showed in Figure 3. First, the Contractor group shows high importance and low satisfaction in 'System should maintain the stable state (SyQ-5)' and 'Information in system could be used without correction (InQ-6)', both of which belong to the domain-A. Therefore, improvement for these factors holds a priority.

In the domain-B, SyQ-3, InQ-5, SyQ-4, InQ-8, and SeQ-8 showed high levels of importance and satisfaction, so their current states should be maintained. However, the importance and satisfaction show similar levels in InQ-4 but are close to average values; thus close observation is required. Besides, 'Information in system should be sufficient (InQ-7)', 'System functions and configuration should be related to required information (InQ-1)', and 'System screen configuration or document formats should be suitable for information use (InQ-2)' showed higher importance and satisfaction than each of their average values. However, satisfaction was relatively lower than importance, so continuous effort to improve the satisfaction is needed. 
In the domain-C, SyQ-1, InQ-9, InQ-10, SeQ-4, SeQ5, and SeQ-6 showed similar levels of importance and satisfaction, indicating maintenance is appropriate. Among other factors in domain-C, 'PMIS should be compatible with other softwares (SyQ-2)' has both the lowest importance and satisfaction. Therefore, further investment for this is risky, but understanding why importance and satisfaction are lower is needed.

Finally, InQ-9, SeQ-7, InQ-3, SeQ-1, and SeQ-2 in the domain-D showed low importance and relatively high satisfaction. Therefore, their current states need to be maintained.

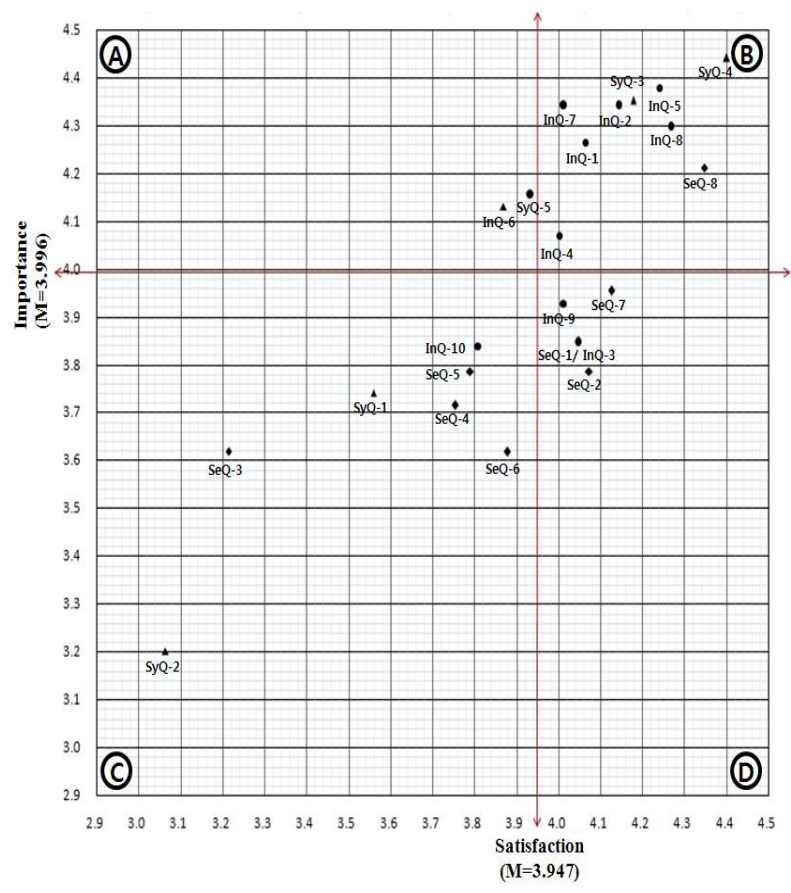

FIGURE III

ISA RESULT OF CONTRACTORS

\section{Summary}

In ISA, the items in the quadrant A are of firstpriority. However, we also need to pay attention to the items that belong to the quadrant $\mathrm{B}$ or $\mathrm{C}$ but are very close to the quadrant $\mathrm{A}$, because they have high possibility to become the first-priority items. Therefore, in this research, we extended the area of the quadrant $\mathrm{A}$ as follows:

- $\operatorname{satisfaction}(\mathrm{x}) \leq$ mean of the satisfaction values+0.1,

- importance $(y) \geq$ mean of the importance values0.1 .

Table 6 shows the summarized results of the quality assessment. The shades in the table indicate that the factors are of first-priority or near to it, i.e., the factors belong to the extended quadrant $\mathrm{A}$.

For the both groups, the urgent items of first-priority are 'InQ-4: PMIS should offer information to users on real time' and 'InQ-6: Information in system could be used without correction', which belong to quadrant A. Other items nearly of first-priority items are 'SyQ-5: System should maintain the stable state', 'InQ-7: Information in system should be sufficient', 'SeQ-1: Reaction of PMIS service provider should be quick in the situation', and 'InQ-9: Information in system should be related to project characteristic and user's role' as a priority factor'.

TABLE III

ISA RESULT OF CMS AND CONTRACTORS

\begin{tabular}{|c|c|c|c|c|}
\hline \multicolumn{2}{|c|}{ Quality Factor } & $\mathrm{CMs}$ & Contractors & Both \\
\hline \multirow{5}{*}{$\begin{array}{l}\text { System } \\
\text { Quality }\end{array}$} & SyQ-1 & $\mathrm{C}$ & $\mathrm{C}$ & $\mathrm{D}$ \\
\hline & SyQ-2 & $\mathrm{C}$ & $\mathrm{C}$ & $\mathrm{D}$ \\
\hline & SyQ-3 & B & B & B \\
\hline & SyQ-4 & B & B & B \\
\hline & SyQ-5 & B & A & B \\
\hline \multirow{10}{*}{$\begin{array}{l}\text { Informati } \\
\text { on Quality }\end{array}$} & InQ-1 & $\mathrm{D}$ & B & $\mathrm{C}$ \\
\hline & InQ-2 & B & B & B \\
\hline & InQ-3 & B & $\mathrm{D}$ & B \\
\hline & InQ-4 & A & B & A \\
\hline & InQ-5 & D & B & B \\
\hline & InQ-6 & B & A & A \\
\hline & InQ-7 & B & B & B \\
\hline & InQ-8 & B & B & B \\
\hline & InQ-9 & $\mathrm{C}$ & $\mathrm{C}$ & $\mathrm{C}$ \\
\hline & InQ-10 & $\mathrm{C}$ & $\mathrm{C}$ & $\mathrm{D}$ \\
\hline \multirow{8}{*}{$\begin{array}{l}\text { Service } \\
\text { Quality }\end{array}$} & SeQ-1 & B & $\mathrm{D}$ & B \\
\hline & SeQ-2 & $\mathrm{D}$ & $\mathrm{D}$ & $\mathrm{C}$ \\
\hline & $\mathrm{SeQ}-3$ & $\mathrm{C}$ & $\mathrm{C}$ & $\mathrm{D}$ \\
\hline & SeQ-4 & $\mathrm{C}$ & $\mathrm{C}$ & $\mathrm{D}$ \\
\hline & SeQ-5 & $\mathrm{C}$ & $\mathrm{C}$ & $\mathrm{D}$ \\
\hline & SeQ-6 & $\mathrm{C}$ & $\mathrm{C}$ & $\mathrm{D}$ \\
\hline & $\mathrm{SeQ}-7$ & $\mathrm{D}$ & $\mathrm{C}$ & $\mathrm{C}$ \\
\hline & SeQ-8 & B & B & B \\
\hline
\end{tabular}

- A: Concentrate Here, B: Keep up the Good Work, C: Low Priority, D: Possible Overkill

For the CM group, the first-priority item is 'InQ-4: PMIS should offer information to users on real time' only. However, there are quite many near-to-firstpriority items: 'SyQ-5: System should maintain the stable state', 'InQ-7: Information in system should be sufficient', 'InQ-2: System screen configuration or document formats should be suitable for information use', 'InQ-6: Information in system could be used without correction', 'InQ-7: Information in system should be sufficient', 'InQ-10: Options for information usage should be various depending on the user's task', 'SeQ-1: Reaction of PMIS service provider should be quick in the situation', and 'SeQ-3: Education for PMIS user should be provided adequately'.

For the Contractor group, the first-priority items are 'SyQ-5: System should maintain the stable state' and 'InQ-6: Information in system could be used without 
correction'. Some other items requiring additional attention are 'InQ-4: PMIS should offer information to users on real time', 'InQ-7: Information in system should be sufficient', and 'InQ-9: Information in system should be related to project characteristic and user's role'.

\section{CONCLUSION}

Although ASP-PMIS has been widely adopted in Korean construction industry, there have been rare research efforts on assessing the quality of the systems. In order to provide indications and implications regarding the key improvement points of ASP-PMIS in Korea, this research selected assessment factors and method, and assessed the quality of ASP-PMIS that is commonly used in Korean construction industry.

According to the assessment results SyQ-5(System should maintain the stable state) and InQ-6(Information in system could be used without correction) are the most urgent items to be improved from the contractor's viewpoint. On the other hand, from the construction manager's viewpoint, InQ-4(PMIS should offer information to users on real time) requires immediate action for improvement. However, considering the both groups assessment, InQ-4(PMIS should offer information to users on real time) and InQ6(Information in system could be used without correction) were selected as the most urgent items to be improved. From these results, we can also understand that users' degree of satisfaction and perceived importance differ to their viewpoints. Hence, PMIS providers need to pay attention to the different users' different assessment results respectively in determining the priority of PMIS improvement. Besides, during the assessment process, it was understood that it is very appropriate to use ISA as an assessment tool for ASPPMIS quality in terms of its easiness of use and analytic capability as well. This is supported by the fact that analyzing the collected data is simple and easy, drawing up the grid and plotting the analyzed data on the grid provides a clear picture of data, and communicating with the plotted results is straightforward.

From the viewpoint of practitioners, this research may be useful because: it introduces a simple and easyto-use tool for assessing the quality of ASP-PMIS with a set of quality assessment factors that are selected from previous researches and empirically tested; it provides the quality assessment results of ASP-PMIS in Korea so that ASP-PMIS providers in Korea can understand the users' opinion on their systems; it also identified that the urgent factors that require immediate attention to improvement.

However, from the academic viewpoint, more efforts need to enhance the quality assessment factors of ASPPMIS, in terms of their relation to the success of ASPPMIS and to the performance of users. In addition, individual analyses of each ASP-PMIS are required so that each system provider can find out the pros and cons of his own systems. Furthermore, assessment systems in terms of instrumental and institutional as well need to be established so that the continuous improvement of ASP-PMIS can be realized.

\section{ACKNOWLEDGE}

This research was supported by Basic Science Research Program through the National Research Foundation of Korea(NRF) funded by the Ministry of Education, Science and Technology(2011-0015446).

\section{REFERENCES}

[1] H.C. Howard, R.E. Levitt, B.C. Paulson, J.G. Pohl, C.B. Tatum, "Computer integration: reducing fragmentation in the AEC industry", Journal of Computing in Civil Engineering, vol. 3, no. 1, pp. 18-32. 1989.

[2] P. Nitithamyong, M.J. Skibniewski, "Web-based construction project management systems: how to make them successful?", Automation in Construction, vol. 13, no. 4, pp.491-506, 2004.

[3] E.M. Rojas, A.D. Songer, "Web-centric systems: A new paradigm for collaboration engineering", Journal of Management Engineering, vol. 15, no. 1, pp. 39-45, 1999.

[4] C.M. Tam, "Use of the Internet to enhance construction communication: Total Information Transfer System", International Journal of Project Management, vol. 17, no. 2, pp. 107-110, 1999.

[5] Z.M. Deng, H. Li, C.M. Tam, Q.P. Shen, P.E.D. Love, "An application of the Internet-based project management system", Automation in Construction, vol.10, no. 2, pp.239-246, 2001.

[6] P. Nitithamyong, M.J. Skibniewski, "Success/Failure factors and performance measures of web-based construction project management systems: Professional viewpoint", Journal of Construction Engineering and Management, vol. 132, no. 1, pp. 80-87, 2006.

[7] M.C. Hurtado, "New survey points to spending growth", Engineering News Record, vol. 246, no. 21, pp. 21, 2003.

[8] Y. Jung, G.E. Gibson, "Planning for computer integrated construction", Journal of Computing in Civil Engineering, vol. 13, no. 4, pp. 217-225, 1999.

[9] F. Pena-Mora, S. Vadhavkar, E. Perkins, T. Weber, "Information technology framework for large-scale projects", Journal of Computing in Civil Engineering, vol. 13, no. 4, pp. 226-237, 1999.

[10] J. Anderson, A. Baldwin, M. Betts, C. Cater, A. Hamilton, E. Stokes, A.T. Thorpe "A framework for measuring IT innovation benefits", Electronic Journal of Information Technology in Construction, vol. 5, pp. 57-72, 2000.

[11] L. Marsh, R. Flanagan, "Measuring the costs and benefits of information technology in construction", Engineering Construction and Architectural Management, vol. 7, no. 4, pp. 423-435, 2000.

[12] F. Pena-Mora, S. Tanaka, "Information technology planning framework for Japanese general contractors", Journal of Management Engineering, vol. 18, no. 3, pp. 138-149, 2002.

[13] P.E.D. Love, Z. Irani, D. Edwards, "Researching the investment of information technology in construction: an examination of evaluation practices", Automation in Construction, vol. 14, no. 4, pp. 569-582, 2005.

[14] R. Stockdale, C. Standing, P.E.D. Love, "Propagation of a parsimonious framework for evaluating information systems in construction", Automation in construction, vol. 15, no. 6, pp. 729-736, 2006.

[15] J.H. Yu, H.S. Lee, "Evaluation Model for Information Systems Benefits in Construction Management Process", Journal of Construction Engineering and Management, vol. 132, no. 10, pp. 1114-1121, 2006.

[16] T. Kern, J. Kreijger, L. Willcocks, "Exploring ASP as sourcing strategy: theoretical perspectives, propositions for practice", The 
Journal of Strategic Information Systems, vol. 11, no. 2, pp. 153177, 2002.

[17] J.H. Yu, H.S. Lee, "Success Factors for Implementing Construction Project Management Information System(PMIS) based on the Characteristics of Construction Management Tasks", Journal of Architectural Institute of Korea, vol. 20, no. 5, pp. 103-110, 2004.

[18] F.D. Davis, "Perceived usefulness, perceived ease of use, and user acceptance of information technology", MIS Quartely, vol. 13, no. 3, pp. 319-340, 1989.

[19] B.Y. Chung, M.J. Skibniewski, C.L.J. Henry, Y.H. Kwak, "Analyzing Enterprise Resource Planning System Implementation Success Factors in the Engineering. Construction Industry", Journal of Computing Civil Engineering, vol. 22, no. 4, pp. 373-382, 2008.

[20] W.H. DeLone, E.R. McLean, "Information system success: The Quest for the Dependent Variable", Information Systems Research, vol. 3, no. 1, pp. 60-95, 1992.

[21] W.H. DeLone, E.R. McLean, "The DeLone and McLean Model of Information system success: A ten-year update", Journal of Management Information Systems, vol. 19, no. 4, pp. 9-30, 2003.

[22] V. Venkatesh, F.D. Davis, "Extrinsic and intrinsic motivation to use computers in the work place", Journal of Applied Psychology, vol. 22, no. 14, pp. 1111-1132, 2000.

[23] L. Raymond, F. Bergeron, "Project Management Information Systems: An Empirical Study of Their Impact on Project Managers and Project Success", International Journal of Project Management, vol. 26, no. 2, pp. 213-220, 2008.

[24] H.Y. Lin, P.Y. Hsu, "ERP Systems Success: An Integration of IS Success Model and Balanced Scorecard", Journal of Research and Practice in Information Technology, vol. 38, no. 3, pp. 215228, 2006.

[25] P.B. Seddon, "A respecification and extension of the DeLone and McLean model of IS success", Information Systems Research, vol. 8, no. 3, pp. 240-252, 1997.

[26] P.B. Seddon, M.Y. Kiew, "A partial test and development of Delone and Mclean's model of IS success", Australian Journal of Information Systems, vol. 4, no. 1, pp. 90-104, 1994.

[27] L.F. Pitt, R.T. Watson, C.B. Kavan, "Service Quality: A Measure of Information Systems Effectiveness", MIS Quartely, vol. 19, no. 2, pp. 319-340, 1995.

[28] B.L. Myers, L.A. Kappelman, V.R. Prybutok, "A comprehensive model for assessing the quality and productivity of the information systems function: Toward a theory for Information systems Assessment", Information Resources Management Journal, vol. 10, no. 1, 1997.

[29] Y.S. Jung, C.H. Jung, "An Empirical Analysis on the Success Factors of ASP Services”, Information System Research, vol. 14, no. 2, pp. 25-53, 2005.

[30] G. Kim, "A Scale Development for Measuring User Satisfaction with GKMS", Journal of the Korea Association for Policy Analysis and Evaluation, vol. 17, no. 4, pp. 117-148, 2007.

[31] J.H. Park, J.G. Kim, J.W. Kim, H.S. Lee, "Deriving an ASP Success Model: An application to Small Business", Business Information Research, vol. 14, no. 1, pp. 43-58, 2004.

[32] M.H. Jeo, C.K. Lee, "An Empirical Analysis on Success Factor and Success Model of Information System: Focus on a local government", Journal of Korea Administration, vol. 31, no. 1, pp. $145-162,1997$.

[33] J.G. Edward, B. Glassberg, Y. J. Kim, S. Lawrence, S. K. Shin, "An experimental investigation of Web-based information systems success in the context of electronic commerce", Decision Support Systems, vol. 39, no. 3, pp. 485-503, 2005.

[34] C. Liu, K.P. Arnett, "Exploring the factors associated with web site success in the context of electronic commerce", Information \& Management, vol. 38, no. 1, pp.23-33, 2000.

[35] Y.C. Han, S.T. Lim, "An Empirical Study on Evaluating Effectiveness of Information System", Journal of Management Research, vol. 12, no. 1, pp. 257-288, 1997.

[36] D.P. Ballou, H.L. Pazer, "Cost/quality tradeoffs for control procedures in information systems", Omega, vol. 15, no. 6, pp. 509-521, 1987.
[37] A. Parasuraman, V.A. Zeithaml, L.L. Berry, "SERVQUAL: A multi-item scale for measuring consumer perceptions of service quality", Journal of Retailing, vol. 64, no. 1, pp. 14-40, 1988.

[38] J. Pallant, "SPSS Survival Manual", Open University Press, Buckingham and Philadelphia, 2001.

[39] J.F. Hair, L. Ronald, R.E.A. Tatham, B. William, "Multivariate Data Analysis, Multivariate Data Analysis", Prentice-Hall International, 1998.

[40] J.C. Nunnally, I.H. Bernstein, "Psychometric Theory", McGrawHill, New York, 1978.

[41] H.F. Kaiser, "A second generation little jiffy", Psychometrika, vol. 35, no. 4, pp. 401-415, 1970.

[42] M.S. Bartlett, "A note on the multiplying factors for various chi square approximations", Journal of the Royal Statistical Society, vol. 16, no. 2, pp. 296-298, 1954.

[43] M.J. Norusis, "SPSS for windows, Professional Statistics, Release 5", SPSS Inc., Chicago, 1992.

[44] B. Li, A. Akintoye, P.J. Edwards, C. Hardcastle, "Critical success factors for PPP/PFI projects in the UK construction industry", Construction Management and Economics, vol. 23, no. 5, pp. 459-471, 2005.

[45] T. Aksorn, B.H.W. Hadikusumo, "Critical success factors influencing safety program performance in Thai construction projects", Safety Science, vol. 46, no. 4, pp. 709-727, 2008.

[46] J.C. Nunnally, I.H. Bernstein, "Psychometric Theory", McGrawHill, New York, 1978.

[47] S.K. Lee, J.H. Yu, "Critical Success Factors for Project Management Information System in Construction", Journal of Construction Engineering and Project Management, vol. 1, no. 1, pp. 25-30, 2011.

[48] S. Hudson, G. A. Miller, P. Hudson, "The Role of Research in Improving Tourism and Hospitality Services: Measuring Service Quality”, CABI Publications, 2006.

[49] J.A. Matilla, J.C. James, "Importance-Performance analysis", Journal of Marketing, vol. 41, no. 3, pp. 77-79, 1977.

[50] H. Oh, "Revisiting importance-performance analysis", Tourism Management, vol. 22, no. 6, pp. 617-627, 2001.

[51] J. Tonge, S.A. Moore "Importance-satisfaction analysis for marine-park hinterlands: A Western Australian case study", Tourism Management, vol. 28, no. 3, pp.768-776, 2007.

[52] J.W. Park, Y.S. Lee, K.W. Park, "A study on the importance and satisfaction of Airline service quality", Journal of the Korean Contents Association, vol. 8, no. 2, pp. 164-172, 2008.

[53] Y.M. Jung, Y.K. Kim, S.S. Lee, "A Study on the Measurement and Improvement of Academic Library Service Quality by ISA(Importance-Satisfaction Analysis)", Journal of Korean Library and Information Science Society, vol. 41, no. 1, pp. 255272, 2010.

[54] S.H. Park, D.Y. Kwak, B.W. Chung, "Importance-Satisfaction Analysis of Tourist Gala: Evaluation of Boryong Mud Festival", The Tourism Sciences Society of Korea, vol. 32, no. 4, pp. 145$161,2008$.

[55] T.H. Kim, J.M. Ha, J.M. Lim, J.J. Park, "An analysis on indicator of water taxi user service in seoul using Importance Performance Analysis(IPA)", Journal of Korean Society of Civil Engineers, vol. 29, no. 5, pp. 587-595, 2009.

[56] A. Parasuraman, V. Zeithaml, L.L. Berry, "A conceptual model of service quality and its implications for future research", Journal of Marketing, vol. 49, no. 4, pp. 41-50, 1985.

[57] S. Llosa, J.L. Chandon, C. Orsingher, "An empirical study of SERVQUAL's dimensionality", The Services Industries Journal, vol. 18 , no. 2 , pp. 16-44, 1998.

[58] R. Ladhari, "A review of twenty years of SERVQUAL research", International Journal of Quality and Service Sciences, vol. 1, no. 2, pp. 172-198, 2009. 